\title{
Ice-sheet mass balance: assessment, attribution and prognosis
}

\author{
Richard B. ALLEY, Matthew K. SPENCER, Sridhar ANANDAKRISHNAN \\ Department of Geosciences, and PSICE Center, Earth and Environmental Systems Institute, \\ The Pennsylvania State University, University Park, PA 16802-7501, USA \\ E-mail: rba6@psu.edu
}

\begin{abstract}
Contrary to prior expectations that warming would cause mass addition averaged over the Greenland and Antarctic ice sheets and over the next century, the ice sheets appear to be losing mass, at least partly in response to recent warming. With warming projected for the future, additional mass loss appears more likely than not.
\end{abstract}

\section{INTRODUCTION}

Ice sheets and sea level occupy an increasingly important place in discussion of wise response to issues of energy and global warming (e.g. Hansen, 2005). The issue is considered by high government officials and generates much interest from the press (the authors have been having hundreds of press contacts per year, for example, and anecdotal evidence indicates that numerous members of the glaciological community are similarly engaged).

Based on discussions with policy-makers and with members of the press and the public, many of these people expect the glaciological community to develop a predictive ability for ice sheets and sea level (as well as for mountain glaciers, permafrost, etc.): given a scenario for future greenhouse-gas emissions and other climate forcings, what is the resulting scenario of sea-level change, with usefully small uncertainties? Considering the potentially large changes in sea level, and the large concentrations of wealth and population near the coasts, the sea-level effects are important and may prove to be dominant in assessments of long-term impacts and in decisions of optimal paths of mitigation and adaptation relative to greenhouse-gas emissions.

Unfortunately, despite the remarkable pace of discovery, it is rather clear that our community is not yet able to produce such scenario-based sea-level projections with uncertainties sufficiently small to please many people, and we may not be especially close to this goal, as discussed below. This inability focuses attention on the history of the ice sheets, and especially on the instrumentally observed history. Scientists, policy-makers and the public all recognize that something that has happened, and is happening, must be possible, and that extrapolation of past and ongoing trends can sometimes produce useful insights.

Here we briefly summarize the state of balance of the ice sheets, discuss uncertainties and consider causes of changes. We find that warming-induced ice-sheet shrinkage is probably occurring, and that this may provide useful guidance for assessing future changes.

\section{ICE-SHEET MASS BALANCE}

In assessing the state of our field, Houghton and others (2001) highlighted the large uncertainties, but found a central estimate that the net ice-sheet response to warming would be slight growth averaged over the next century. Snowfall increase on Antarctica and central Greenland was projected to exceed increase in low-altitude melting on
Greenland, with ice-flow changes small, mostly restricted to Greenland and serving to reduce flow to the ocean to supply ice loss by calving of icebergs. (Note that a possible longterm trend of Antarctic shrinkage in response to the end of the last ice age was considered separately.)

Figures 1 and 2 summarize recently published estimates of the ice-sheet mass balance for Greenland and Antarctica. Following Thomas and others (2006), each box extends horizontally from the starting time to the ending time covered by a mass-balance estimate, and vertically from the estimated mass balance minus the stated uncertainty to the estimated mass balance plus the stated uncertainty. In most cases, the stated uncertainties do not easily translate into standard deviations ( $1 \sigma$ or $2 \sigma$ ), because some terms contributing to the uncertainty could not be addressed with rigorous statistical sampling. In the following, we discuss some of the sources of error and possible explanations for differences. It is not our purpose to cast doubt on this important and careful science, but rather to identify issues and possibilities for improvement. We also seek to assess the common signal underlying the varied results in the figures.
Altimetry
Altimetry is conducted from aircraft using laser ranging (Krabill and others, 2004; Thomas and others, 2006), and from satellite using laser (Thomas and others, 2006) or radar (Zwally and others, 2005) sensors. The narrow laser footprint requires interpolation, and reflections from clouds compli- cate interpretation especially for the satellite-borne lasers (Shuman and others, 2006), as does the so-far limited lifetime of those lasers.
Radar samples larger areas, has operated reliably for longer times, and penetrates cloud cover. Radar also penetrates the snow surface to a varying depth (e.g. Rémy and others, 2001). Radar altimeters were designed to operate over the nearly planar ocean, and the sloping flanks of ice sheets cause difficulties with off-nadir reflections. As discussed by, for example, Jezek and Alley (1988), Arthern and others (2001) and Rémy and others (2001), change in surface roughness or in near-surface layering or density can affect the waveform shape returned to the satellite and thus the computed range, even if the range is not changing.
Commonly, power returned to the satellite from the surface is found to correlate with estimated range (distance), when radar returns from a given point on the surface are compared over time (e.g. Wingham and others, 1998). It is reasonable to expect that changing surface character will change both the returned power and the single range number that is calculated from the information in the 




Fig. 1. Mass-balance estimates for Greenland. Following Thomas and others (2006), age span over which the measurement applies is indicated by vertical bars, with horizontal bars placed at (mean + uncertainty) and (mean - uncertainty) as reported in papers. Code: B (orange; Box and others, 2006), surface mass balance, using stated trend in accumulation, assumed-constant ice-flow discharge, and standard error on regression of accumulation trend, with arrow added to show that additional loss from ice-flow acceleration is indicated; H (brown; Hanna and others, 2005), surface mass balance, with arrow as for Box and others (2006) indicating ice-flow acceleration; $\mathrm{T}$ (dark green; Thomas and others, 2006), laser altimetry, showing new results and revision of Krabill and others (2004) to include firn densification changes; Z (violet; Zwally and others, 2006), primarily radar altimetry, with uncertainty spanning elevation changes as firn and as ice; R (red; Rignot and Kanagaratnam, 2006), ice discharge combined with surface mass balance; V (blue; Velicogna and Wahr, 2005), GRACE gravity; RL (blue; Ramillien and others, 2006), GRACE gravity; C (blue; Chen and others, 2006b), GRACE gravity; L (blue; Luthcke and others, 2006), GRACE gravity. The estimate for the central part of the ice sheet from Johannessen and others (2005) (J, magenta) is included dashed for comparison; inland thickening and coastal thinning are indicated by many of the studies.

returned waveform. Workers typically remove range changes correlated with returned-power changes, presuming those range changes are artifacts. Zwally and others (2005), for example, removed all range variation that correlated with returned-power variation with a correlation coefficient of 0.2 or higher, but limited corrections to between -0.2 and $0.7 \mathrm{~m} \mathrm{~dB}^{-1}$ to avoid outliers. (We found the paper of Zwally and others (2005) especially helpful in detailing the corrections used, their magnitudes and signs and the effects of alternate assumptions on the analysis.)

Zwally and others (2005) found the total rangepower correction averaged over an ice sheet to be small $\left(-0.02 \mathrm{~cm} \mathrm{a}^{-1}\right.$ for changes in the surface elevation of Greenland, $-0.34 \mathrm{~cm} \mathrm{a}^{-1}$ for grounded ice in Antarctica) but with a fairly large spatial variability (standard deviations of $2.36 \mathrm{~cm} \mathrm{a}^{-1}$ for Greenland and $2.94 \mathrm{~cm} \mathrm{a}^{-1}$ for Antarctica). Single-site corrections are of the same magnitude as remaining signals. Zwally and others noted that for Byrd Station, West Antarctica, this correction shifts an apparent thickening of $5.4 \pm 1.3 \mathrm{~cm} \mathrm{a}^{-1}$ to a thinning of $1.2 \pm 0.7 \mathrm{~cm} \mathrm{a}^{-1}$, and the corrected value is consistent with independent evidence from surface global positioning system (GPS) measurements but the uncorrected value is not. Similarly, Wingham and others (1998), for $1^{\circ} \times 1^{\circ}$ regions in inland Antarctica, obtained a mean correction of $1.1 \mathrm{~cm} \mathrm{a}^{-1}$, a standard deviation

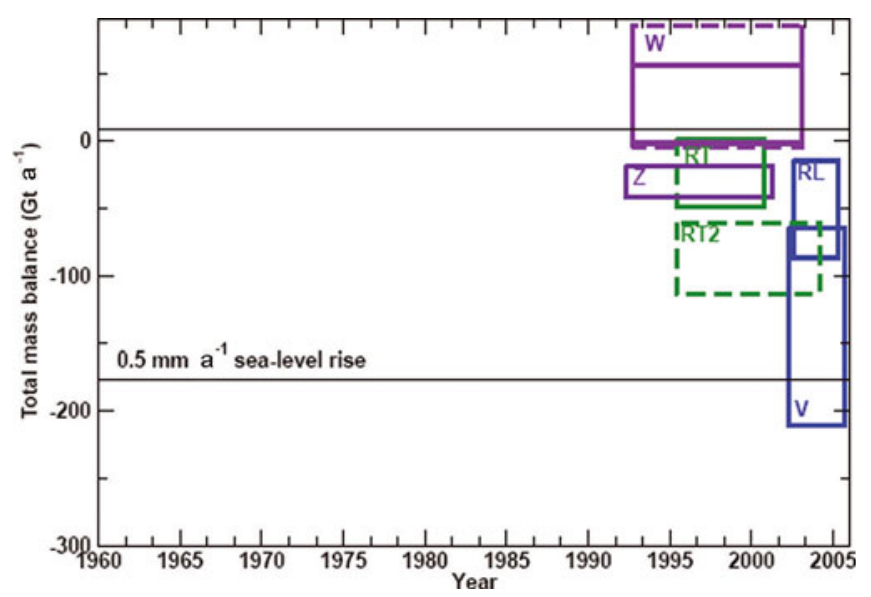

Fig. 2. Mass-balance estimates for grounded ice of Antarctica. Following Thomas and others (2006), age span over which the measurement applies is indicated by vertical bars, with horizontal bars placed at (mean + uncertainty) and (mean - uncertainty) as reported in papers. Code: Z (indigo; Zwally and others, 2005), primarily radar altimetry, with uncertainties including assignment of thickness changes to firn or to ice; W (violet; Wingham and others, 2006), radar altimetry over $72 \%$ of ice sheet, with the preferred error bars shown solid and a wider set of error bars reported by the authors shown dashed; RT (dark green; Rignot and Thomas, 2002), ice discharge and surface mass balance, with dashed older end line because some of the accumulation-rate data extend beyond the time limit shown; RT2 (dark green; Rignot and Thomas, 2002), updated to include additional mass losses indicated by Thomas and others (2004) and Rignot and others (2005), dashed because the original authors did not produce this as a whole-ice-sheet estimate; V (blue; Velicogna and Wahr, 2006), GRACE gravity; RL (blue, Ramillien and others, 2006), GRACE gravity.

of $6.1 \mathrm{~cm} \mathrm{a}^{-1}$ and a correction ranging from -25.7 to $38.8 \mathrm{~cm} \mathrm{a}^{-1}$, based on applying a range-power correlation from June 1993 to December 1994 to a 5 year window. Davis and Ferguson (2004) provided additional insight to the range-power correction, seasonal vs interannual changes, spatial distribution in Antarctica, and more.

We believe, however, that it is virtually unavoidable that some climate changes affecting actual range (through increased or decreased snowfall, or increased or decreased temperature affecting the rate of expulsion of air during density increase) will also affect the surface character (through effects on density, layering, melt-layer formation and burial, and surface roughness). Hence, the range-power correction is highly likely to remove signal in at least some places, and the regional nature of some climate changes and some trends means that a near-zero ice-sheet average could mask important signals. Despite a literature much richer than can be cited in a short paper, comprehensive treatments synthesizing 'ground-truth' measurements of roughness, surface snow characteristics, radar-derived and independently derived (e.g. by GPS surveying on the surface) elevation changes are generally not available. Even the sign of any induced error is not obvious for this correction.

Long-term monitoring of elevation changes requires accurate intercomparison of datasets collected at different times, a problem that is considered carefully in aerogeophysics, that will be important if another laser-altimetry satellite is launched, and that has mattered in radar altimetry. Zwally and others (2005) used an empirical correction to relate datasets from the European Remote-sensing Satellites 
ERS-1 and ERS-2, which for Greenland required lowering ERS-2 data by $30.7 \mathrm{~cm}$. Johannessen and others (2005), using a different empirical technique, obtained a corresponding value of $21.5 \mathrm{~cm}$, although differences in area of coverage in the two studies may explain some or all of this difference in correction. Note that the effect of the Zwally and others correction is larger than the remaining signal, and the difference between the Johannessen and others and Zwally and others corrections (if arising from a true difference and not an area-of-coverage effect) is about as large as the signal, highlighting the importance of the correction. (Work by Davis and others (2005), Johannessen and others (2005), Zwally and others (2005) and Wingham and others (2006) based on ERS-1 and ERS-2 typically spans 1992-2002, or similar time intervals.)

Changes in air storage in the near-surface layers are important: an estimated rate of ice-sheet thickness change may represent ice, or as much as two-thirds air and only one-third ice, with a corresponding uncertainty in effect on sea level (e.g. Wingham, 2000; Cuffey, 2001). Using a firn densification model, Arthern and Wingham (1998) estimated that for conditions corresponding to Site 2, Greenland, a $1{ }^{\circ} \mathrm{C}$ warming would cause an equilibrium thinning of the firn (expulsion of air) of $0.53 \mathrm{~m}$, with half of the change completed over 45 years. In comparison, a 10\% increase in accumulation rate would increase air storage in the firn by $0.46 \mathrm{~m}$, with half of the change completed in only 6 years (yielding an average thickening rate over the first 6 years following the perturbation of almost $8 \mathrm{~cm} \mathrm{a}^{-1}$, vs thinning of just over $1 \mathrm{~cm} \mathrm{a}^{-1}$ averaged over the first 45 years for the temperature response). Accumulation probably increases somewhat less than $10 \%{ }^{\circ} \mathrm{C}^{-1}$ (e.g. Kapsner and others, 1995), but any increase in excess of $1-2 \%{ }^{\circ} \mathrm{C}^{-1}$ would cause the accumulation-rate changes to initially dominate, according to the Arthern and Wingham (1998) model. The model of Zwally and Li (2002) is somewhat more temperature-sensitive. Analyses by McConnell and others (2000) suggested that elevation changes in central Greenland were primarily controlled by changes in accumulation rate, although without separating the effects of variations in mass accumulation from variations in the density of that accumulation.

Zwally and others (2005) used estimated temperatures from satellite data and a firn densification model to correct elevation changes for the effect of temperature on the rate of densification. Warming in Greenland drove a calculated surface lowering of $1.7 \mathrm{~cm} \mathrm{a}^{-1}$ in Greenland $\left(23 \mathrm{Gt} \mathrm{a}^{-1}\right.$ of ice equivalent), with a surface lowering of $1.6 \mathrm{~cm} \mathrm{a}^{-1}$ for the West Antarctic ice sheet $\left(28 \mathrm{Gta}^{-1}\right)$ and a rise in the East Antarctic ice sheet of $0.2 \mathrm{~cm} \mathrm{a}^{-1}\left(19 \mathrm{Gta}^{-1}\right)$. Zwally and others did not make a corresponding correction for accumulation-rate effects on near-surface density. Hence, as discussed by Zwally and others, if temperature and accumulation rate rose recently at a site where no thickness change was measured, the authors would calculate that the surface should be dropping in response to the warming, and would infer that the lack of elevation change demonstrated increase of ice thickness at that site over that time interval.

However, in recognition of the possible effects of accumulation rate on near-surface density, Zwally and others also reported the mass balance assuming that the inland changes in Greenland, and the changes in Antarctica, were firn rather than ice. The effect was to shift Greenland from growing by $10.8 \pm 2.6 \mathrm{Gta}^{-1}$ to shrinking by $18.4 \pm 2.0 \mathrm{Gt} \mathrm{a}^{-1}$, and to shift Antarctica from shrinking by $30.3 \pm 12 \mathrm{Gt} \mathrm{a}^{-1}$ to shrinking by $13.6 \pm 5.4 \mathrm{Gt} \mathrm{a}^{-1}$ for firn of $400 \mathrm{~kg} \mathrm{~m}^{-3}$. Note that there is only a small effect on the combined mass balance of the ice sheets if both firn numbers (combined shrinkage of $32 \pm 6 \mathrm{Gta}^{-1}$ ) or both ice numbers (combined shrinkage of $19 \pm 12 \mathrm{Gta}^{-1}$ ) are used. However, as discussed below, the strong evidence for recent increase in accumulation rate in inland Greenland, but lack of strong evidence for a corresponding increase in Antarctica, argues that something closer to the firn number for Greenland and to the ice number for Antarctica may be more appropriate; simply using those numbers would give a combined mass balance over the 1992-2002 interval of shrinkage by $49 \pm 12 \mathrm{Gta}^{-1}$. In the Zwally and others study, the uncertainty related to nearsurface density change thus is as large as about $30 \mathrm{Gta}^{-1}$ for the ice sheets.

Thomas and others (2006) assumed a uniform surface lowering for Greenland of $1 \mathrm{~cm} \mathrm{a}^{-1}$ in response to warminginduced densification, and then assigned measured icesheet thickening inland a density of $600 \mathrm{~kg} \mathrm{~m}^{-3}$ to allow for increased air storage near the surface in response to increased accumulation rate, and $900 \mathrm{~kg} \mathrm{~m}^{-3}$ near the coast where ablation removes all of the seasonal snow. To the best of our knowledge, no one has yet conducted a full modeldriven correction for temperature and accumulation-rate effects.

Isostatic corrections can affect altimetry as well. Discussion is included in the next subsection.

\section{Gravimetry}

The GRACE (Gravity Recovery and Climate Experiment, managed jointly by NASA and the German Aerospace Research Center (DLR)), was launched in March 2002 (Tapley and others, 2004), and offers a great opportunity for an independent measure of ice-sheet mass balance. A breakaway group in a bicycle race will, on cresting a steep climb and starting the descent, move away from the stillclimbing peloton, but the peloton will close the gap when the breakaway begins the next climb. A record of the positions of the breakaway and the peloton would reveal the locations of the mountains to an attentive observer. In the same way, the changing positions of the GRACE satellites reveal subtle features of the Earth's gravity field reflecting mass differences, and time evolution can reveal changes in mass storage.

Errors arise from numerous sources, many of which are considered by Wahr and others (2006). The GRACE 'footprint' is perhaps $1000 \mathrm{~km}$ across, so changes well beyond the region of interest can be important. Different techniques exist for making this correction and have been used by the different groups working on the ice-sheet mass balance. Inspection of the four GRACE-based estimates in Figure 1 highlights the magnitudes of some of the remaining difficulties. The short time over which the satellites have been operating (since 2002) is of considerable concern as well.

Changes in bedrock elevation, primarily arising from isostatic response to past changes in mass loading, play a larger role in gravimetry than in altimetry. Because flowing mantle rocks have density $\sim 3300 \mathrm{~kg} \mathrm{~m}^{-3} \mathrm{vs} \sim 910 \mathrm{~kg} \mathrm{~m}^{-3}$ for ice, a given elevation change will affect the gravitational field $\sim 3.6$ times more if caused by isostasy than if caused by change in ice thickness.

For Greenland, Zwally and others (2005) combined results from three isostatic treatments to estimate ongoing 
isostatic uplift of $0.6 \pm 0.4 \mathrm{mma}^{-1}$, with faster uplift of $5.4 \pm 0.07 \mathrm{~mm} \mathrm{a}^{-1}$ for Antarctica. Assuming the Antarctic value is accurate, failure to have included it would have biased mass balance of Antarctica estimated from altimetry by $\sim 60 \mathrm{Gta}^{-1}$, but mass balance estimated from gravimetry by almost $220 \mathrm{Gta}^{-1}$. As noted by Chen and others (2006a), 'estimates of Antarctic snow/ice mass rates from GRACE data are completely dependent on the adopted PGR [postglacial rebound] model, with uncertainties that might be on the order of $100 \%$ '. Using GRACE data, Chen and others found a region of rapid mass loss in West Antarctica, and a region of rapid mass gain in East Antarctica, with a net near zero; however, the authors argued that independent glaciological and meteorological data point to the West Antarctic anomaly as being a feature of ice-mass loss, and the East Antarctic anomaly as being an error in the isostatic adjustment modeling.

Note that even for altimetry, the uncertainties in isostatic behavior are important. Zwally and others (2005) estimated an isostatic uplift rate for the region covered by ERS radar altimetry of $4.5 \mathrm{~mm} \mathrm{a}^{-1}$ (and a slightly larger rate of $5.4 \mathrm{~mm} \mathrm{a}^{-1}$ for the entire grounded ice sheet) vs the value of $1.7 \mathrm{~mm} \mathrm{a}^{-1}$ for the ERS-covered region adopted by Wingham and others (2006). The areas of ERS data coverage in the two studies were not identical although quite similar, so these numbers are not exactly comparable. Nonetheless, had the Zwally and others isostatic adjustment been adopted by Wingham and others, their central estimate of ice-sheet growth would have been reduced by more than half.

\section{Other geodetic constraints}

Munk (2002) noted that joint analysis of the history of changing length of day from eclipse records, the related ongoing changes in the spherical harmonic coefficients of the geopotential, and changes in the rotation vector of the planet (true polar wander) apparently ruled out the possibility of a large mass flux from the ice sheets to the oceans. (Motion of mass from the near-polar ice sheets to the more equatorial oceans slows the Earth's rotation like a spinning ice skater extending her arms; the motion of mass associated with ongoing isostatic response to the end of the last ice age partially offsets this; and the off-spin-axis changes in mass flux excite true polar wander.) However, Mitrovica and others (2006) argued that use of measured rather than calculated shape of the planet in the calculations (including 'bulging' of the Earth at the equator from non-rotational causes such as mantle convection) weakens the Munk triple constraint, allowing (but not necessarily requiring) accelerated late-20th-century contribution to sea-level rise from melting of land ice up to $\sim 360 \mathrm{Gta}^{-1}\left(\sim 1 \mathrm{~mm} \mathrm{a}^{-1}\right.$ of sealevel equivalent).

\section{Input-output}

Rapid improvements in atmospheric analyses are narrowing uncertainties on surface-balance terms, matching improvements in ice-flow measurements, and rapidly reducing errors that once seemed almost insurmountable.

For Greenland, the recent analyses of Hanna and others (2005) and Box and others (2006) used European Centre for Medium-range Weather Forecasts (ECMWF) operational and re-analysis products. Hanna and others (2005) downscaled the global fields to Greenland surface observations using fuzzy interpolation, and Box and others (2006) embedded the mesoscale model PolarMM5 in the global fields and adjusted to match surface observations. Complete surface mass-balance calculations were made (snowfall, sublimation, meltwater generation, runoff and refreezing, etc.). Large interannual variability complicates interpretation of trends, and important baseline differences still exist (see Fig. 1).

For Antarctica, similar efforts are less accurate owing to the larger size of the ice sheet, greater uncertainties in the atmospheric products, and fewer and shorter ground-truth records. Studies using US National Centers for Environmental Prediction (NCEP), ECMWF and Japanese re-analysis products, and two different mesoscale models driven by ECMWF re-analysis and one by NCEP re-analysis, found no strong trends in Antarctic accumulation from 1980 to 2004 (Van de Berg and others, 2006) or for 1985-2001 (Monaghan and others, 2006), although the uncertainties remain large.

Ice-flow output must be added to surface fluxes. This requires knowledge of ice velocity and thickness, collected where flotation begins. Surface velocities may be obtained in many ways, but satellite data are especially useful, including synthetic aperture radar (SAR) interferometry, speckle tracking and feature tracking. Thicknesses are from ice-penetrating radar. Uncertainties are noted in Thomas and others (2004) and Rignot and Kanagaratnam (2006), among others. These uncertainties include the difficulty of obtaining thickness data encircling an ice sheet at the grounding line at the same time as velocity measurements are made; depth variation of velocity, especially where surveys are not exactly at the grounding line; and questions about seasonal variations, near-surface density variations, etc.

\section{Synopsis}

There exists no optimal technique to measure ice-sheet mass balance. Important errors are associated with all of the available techniques. For some, the sign of a bias can be estimated: for example, a study relying only on radar altimetry, with its large footprint and difficulty of measuring steep surfaces, is likely to underestimate thinning localized in narrow troughs draining steep coastal regions (Thomas and others, 2006). In other cases, even the sign of the bias is not clear.

The commonality of signal detected by different techniques seems important. The techniques are mostly independent. (Altimetry and gravimetry do share dependence on isostatic calculations, but the different sensitivities partially alleviate this problem.) From inspection of Figure 1, it is difficult to avoid the conclusion that the Greenland ice sheet was losing mass at an accelerating rate over the last decade or longer. This conclusion is strengthened if one remembers that the $\mathrm{H}$ and $\mathrm{B}$ records in the figure (Hanna and others, 2005; Box and others, 2006) do not include the known iceflow accelerations (hence, arrows are added to those balance indications in the figure). Also, the known increase in accumulation rate in high-elevation regions leads one to expect that air storage in the near-surface layers has increased there, so that changes in elevation there are occurring at lower density than ice, favoring the shrinkingice-sheet rather than growing-ice-sheet side of the $Z$ box. Remembering that $360 \mathrm{Gt}$ is $\sim 1 \mathrm{~mm}$ of sea-level equivalent, it appears that uncertainties have not yet been reduced to $0.1 \mathrm{~mm} \mathrm{a}^{-1}$ of sea-level change.

The situation in Antarctica is less clear. Because no strong trend in accumulation rate has been detected, the lower end 
of the $Z$ box (elevation changes are ice) may be preferred. The different times of collection of some of the datasets may be biasing the results. We believe that the favored interpretation ( $>50 \%$ confidence) includes a recent shift to or acceleration in net mass loss, but we believe that the level of confidence is not especially high.

\section{ATTRIBUTION}

For Greenland, attribution seems relatively straightforward. For Antarctica, clues are available, but conclusions are less clear, in part because of the fuzzy nature of the signal.

\section{Greenland}

In Greenland, the atmospheric and surface mass-balance calculations indicate an increase in melt-season temperature, occurring with increasing area of melting, increasing meltwater runoff, increasing snow accumulation rate and decreasing surface mass balance (Hanna and others, 2005; Box and others, 2006; also see Hall and others, 2006). Interannual variability is high, so the confidence in some of these trends is not especially high, but these results are at least more likely than not in all cases. A link between the warming and the shift to negative surface mass balance appears strong.

Cause and effect is somewhat harder to demonstrate for the accelerations in ice-flow velocity, although effects of warming appear to be the most likely explanation. Thomas and others (2004) showed mostly by a process of elimination that the large thinning of the floating tongue of Jakobshavns Isbræ, Greenland, preceding its break-up was linked to increased basal melting, suggesting the influence of warmer waters, with increased flow velocity and thinning following. Luckman and others (2006) noted the similar behavior of Helheim and Kangerdlugssuaq glaciers on the east coast of Greenland: 'The period of continued warming and thinning appears to have primed these glaciers for a step-change in dynamics not included in current models. We should expect further Greenland outlet glaciers to follow suit' (abstract). The increased meltwater runoff from the surface also is probably contributing to increased iceflow velocity through increased basal lubrication following drainage through moulins in at least some places (Zwally and others, 2002).

Please note that we have made no attempt to attribute the warming to human forcing vs natural variations, nor have we addressed the issue of whether past natural warming has caused past ice-sheet mass loss. We have not tried to separate 'fluctuation' from 'trend'. We simply note that the evidence favors the interpretation that the Greenland ice sheet has experienced a recent acceleration of mass loss in response to the effects of recent environmental warming, with melt-season air temperatures and associated effects on energy balance probably contributing, along with ocean temperatures.

\section{Antarctica}

For Antarctica, strong regional temperature trends, large variability but weak continent-wide temperature trends are indicated (e.g. Thompson and Solomon, 2002; Schneider and others, 2006). (Large fluctuations are also observed in Greenland records.) Because of the restricted nature of Antarctic surface melting and the small runoff, any continent-wide temperature change is not especially important in mass-balance modeling. Little trend is observed in accumulation rates, but with much uncertainty (Monaghan and others, 2006).

Strong warming has been observed in the Antarctic Peninsula region, contributing to the break-up of the Larsen $B$ and Wordie ice shelves and associated ice-flow acceleration (e.g. Morris and Vaughan, 2003; Scambos and others, 2004). Enhanced basal melting, probably from warmer waters but possibly from changes in oceanic circulation, appears to have contributed to loss of the Larsen B and to thinning of ice shelves in the Pine Island Bay region (Shepherd and others, 2003, 2004), allowing ice-flow speed-up (e.g. Dupont and Alley, 2005).

Huybrechts (2002) found a long-term trend of ice-sheet shrinkage (by about $90 \mathrm{Gta}^{-1}$, a notable amount relative to the imbalances suggested in Figure 2) in most of his modeling sensitivity studies; however, the trend was estimated to end within the next millennium, and timing of deglacial forcing is probably not known to better than a millennium (such that the trend might be larger, or might be nearly finished; notes about model behavior, below, are at least suggestive that the real ice sheet may change more rapidly than the model one, favoring completion of the trend already).

Given the large remaining uncertainties in mass balance, accumulation-rate changes and long-term trend, one might still argue that increasing accumulation rate in response to warming is increasing ice-sheet mass more than accelerated coastal flow is decreasing that mass, and that any shrinkage is a result of the long-term trend. However, with a central estimate of little accumulation-rate change to date, a central estimate of recently increased mass loss, and the evidence that warming contributed to this recent increase, it appears to us to be at least more likely than not that the ice sheet has responded to recent near-coastal warming by losing mass.

\section{PROGNOSIS}

The projections of warming adding mass to the ice sheets averaged over the next century were based on state-of-theart ice-sheet flow models forced in various ways. As reviewed briefly by Alley and others (2005), those models did not accurately project the coastal changes that have since occurred around parts of the ice sheets. Explanations may include inadequate forcing in the models (we are confident that the groups engaged in global oceanatmosphere modeling have not produced highly validated projections of oceanic heat transport beneath ice shelves), inadequate resolution in ice-flow models (some ice-flow responses to perturbations scale with ice velocity, so too-low resolution may yield too-slow model response) or inadequate representation of physical processes in the models (with longitudinal-stress transmission in ice streams especially important). Regardless of the correct explanation, until a suite of more accurately forced, more physically complete, higher-spatial-resolution ice-flow models is developed and tested, interpretation of model-based projections merits caution. In particular, the models appear to be less responsive than the ice sheets, perhaps owing to resolution and longitudinal-stress transmission issues. If so, and if nearcoastal warming occurs, then mass loss from ice-flow processes would exceed estimates from models, consistent with the recent changes.

Perhaps the most 'optimistic' result so far is that Antarctic snow accumulation does not seem to have increased greatly 
(Monaghan and others, 2006), but is expected to do so as Antarctic warming spreads inland (Houghton and others, 2001). And, there can be no question that large uncertainties remain about the mass balance of the ice sheets, and about fluctuation vs trend.

Nonetheless, Houghton and others (2001) provided a central estimate that the effect of warming would be to add mass to the ice sheets averaged over this century. Taken together, the ice sheets now appear to be losing mass, at least in part in response to warming, and the community has explanations for the difference between observed and projected behavior. Future warming is projected (Houghton and others, 2001). Details of warming are quite important (ocean vs atmosphere, seasonality, etc.), and future warming may not mimic the pattern of past warming. Nonetheless, based on the evidence presented here, warminginduced shrinkage over the next century of the ice sheets taken together appears more likely than does warminginduced growth.

\section{ACKNOWLEDGEMENTS}

We thank J. Zwally, R. Thomas, J. Mitrovica, other colleagues and reviewers for helpful information. Funding was provided by the US National Science Foundation through grants 0531211, 0440447, 0447235, 0424589 and 0229609, and by the Gary Comer Science and Education Foundation.

\section{REFERENCES}

Alley, R.B., P.U. Clark, P. Huybrechts and I. Joughin. 2005. Icesheet and sea-level changes. Science, 310(5747), 456-460.

Arthern, R.J. and D.J. Wingham. 1998. The natural fluctuations of firn densification and their effect on the geodetic determination of ice sheet mass balance. Climatic Change, 40(4), 605-624.

Arthern, R.J., D.J. Wingham and A.L. Ridout. 2001. Controls on ERS altimeter measurements over ice sheets: footprint-scale topography, backscatter fluctuations, and the dependence of microwave penetration depth upon satellite orientation. J. Geophys. Res., 106(D24), 33,471-33,484.

Box, J.E. and 8 others. 2006 Greenland ice sheet surface mass balance variability (1988-2004) from calibrated polar MM5 output. J. Climate, 19(12), 2783-2800.

Chen, J.L., C.R. Wilson, D.D. Blankenship and B.D. Tapley. 2006 a. Antarctic mass rates from GRACE. Geophys. Res. Lett., 33(11), L11502. (10.1029/2006GL026369.)

Chen, J.L., C.R. Wilson and B.D. Tapley. 2006b. Satellite gravity measurements confirm accelerated melting of Greenland ice sheet. Science, 313(5795), 1958-1960.

Cuffey, K.M. 2001. Interannual variability of elevation on the Greenland ice sheet: effects of firn densification, and establishment of a multi-century benchmark. J. Glaciol., 47(158), 369-377.

Davis, C.H. and A.C. Ferguson. 2004. Elevation change of the Antarctic ice sheet, 1995-2000, from ERS-2 satellite radar altimetry. IEEE Trans. Geosci. Remote Sens., 42(11), 2437-2445.

Davis, C.H., Y. Li, J.R. McConnell, M.M. Frey and E. Hanna. 2005. Snowfall-driven growth in East Antarctic ice sheet mitigates recent sea-level rise. Science, 308(5730), 1898-1901.

Dupont, T.K. and R.B. Alley. 2005. Assessment of the importance of ice-shelf buttressing to ice-sheet flow. Geophys. Res. Lett., 32(4), L04503. (10.1029/2004GL022024.)

Hall, D.K., R.S. Williams, Jr and K.A. Casey. 2006. Satellite-derived, melt-season surface temperature of the Greenland Ice Sheet (2000-2005) and its relationship to mass balance. Geophys. Res. Lett., 33(11), L11501. (10.1029/2006GL026444.)
Hanna, E., P. Huybrechts, I. Janssens, J. Cappelen, K. Steffen and A. Stephens. 2005. Runoff and mass balance of the Greenland ice sheet: 1958-2003. J. Geophys. Res., 110(D13), D13108. (10.1029/2004JD005641.)

Hansen, J.E. 2005. A slippery slope: how much global warming constitutes 'dangerous anthropogenic interference'? Climatic Change, 68(3), 269-279.

Houghton, J.T. and 7 others. 2001. Climate change 2001: the scientific basis. Contribution of Working Group I to the Third Assessment Report of the Intergovernmental Panel on Climate Change. Cambridge, etc., Cambridge University Press.

Huybrechts, P. (2002), Sea-level changes at the LGM from icedynamic reconstructions of the Greenland and Antarctic ice sheets during the glacial cycles, Quat. Sci. Rev., 21(1-3), 203-231.

Jezek, K.C. and R.B. Alley. 1988. Effect of stratigraphy on radaraltimetry data collected over ice sheets. Ann. Glaciol., 11, 60-63.

Johannessen, O.M., K. Khvorostovsky, M.W. Miles and L.P. Bobylev. 2005. Recent ice-sheet growth in the interior of Greenland. Science, 310(5750), 1013-1016.

Kapsner, W.R., R.B. Alley, C.A. Shuman, S. Anandakrishnan and P.M. Grootes. 1995. Dominant influence of atmospheric circulation on snow accumulation in Greenland over the past 18,000 years. Nature, 373(6509), 52-54.

Krabill, W. and 12 others. 2004. Greenland Ice Sheet: increased coastal thinning. Geophys. Res. Lett., 31(2), L24402. (10.1029/ 2004GL021533.)

Luckman, A., T. Murray, R. de Lange and E. Hanna. 2006. Rapid and synchronous ice-dynamic changes in East Greenland. Geophys. Res. Lett., 33(3), L03503. (10.1029/2005GL025428.)

Luthcke, S.B. and 8 others. 2006. Recent Greenland ice mass loss by drainage system from satellite gravity observations. Science, 314(5803), 1286-1289.

McConnell, J.R. and 7 others. 2000. Changes in Greenland ice sheet elevation attributed primarily to snow accumulation variability. Nature, 406(6798), 877-879.

Mitrovica, J.X., J. Wahr, I. Matsuyama, A. Paulson and M.E. Tamisiea. 2006. Reanalysis of ancient eclipse, astronomic and geodetic data: a possible route to resolving the enigma of global sea-level rise. Earth Planet. Sci. Lett., 243(3-4), 390-399.

Monaghan, A.J., D.H. Bromwich and S.-H. Wang. 2006. Recent trends in Antarctic snow accumulation from Polar MM5 simulations. Philos. Trans. R. Soc. London, Ser. A, 364(1844), 1683-1708.

Morris, E.M. and D.G. Vaughan. 2003. Spatial and temporal variation of surface temperature on the Antarctic Peninsula and the limit of viability of ice shelves. In Domack, E., A. Leventer, A. Burnett, R.A. Bindschadler, P. Convey and M. Kirby, eds. Antarctic Peninsula climate variability: historical and paleoenvironmental perspectives. Washington, DC, American Geophysical Union, 61-68. (Antarctic Research Series 79.)

Munk, W. 2002. Twentieth century sea level: an enigma. Proc. Natl. Acad. Sci. USA (PNAS), 99(10), 6550-6555.

Ramillien, G. and 6 others. 2006. Interannual variations of the mass balance of the Antarctica and Greenland ice sheets from GRACE. Global Planet. Change, 53(3), 198-208.

Rémy, F., B. Legrésy and L. Testut. 2001. Ice sheet and radar altimetry. Surv. Geophys., 22(1), 1-29.

Rignot, E. and P. Kanagaratnam. 2006. Changes in the velocity structure of the Greenland Ice Sheet. Science, 311(5673), 986-990.

Rignot, E. and R.H. Thomas. 2002. Mass balance of polar ice sheets. Science, 297(5586), 1502-1506.

Rignot, E. and 9 others. 2005. Recent ice loss from the Fleming and other glaciers, Wordie Bay, West Antarctic Peninsula. Geophys. Res. Lett., 32(7), L07502. (10.1029/2004GL021947.)

Scambos, T.A., J.A. Bohlander, C.A. Shuman and P. Skvarca. 2004. Glacier acceleration and thinning after ice shelf collapse in the 
Larsen B embayment, Antarctica. Geophys. Res. Lett., 31(18), L18402. (10.1029/2004GL020670.)

Schneider, D.P. and 6 others. 2006. Antarctic temperatures over the past two centuries from ice cores. Geophys. Res. Lett., 33(16), L16707. (10.1029/2006GL027057.)

Shepherd, A., D. Wingham, T. Payne and P. Skvarca. 2003. Larsen Ice Shelf has progressively thinned. Science, 302(5646), 856-859.

Shepherd, A., D. Wingham and E. Rignot. 2004. Warm ocean is eroding West Antarctic Ice Sheet. Geophys. Res. Lett., 31(23), L23404. (10.1029/2004GL021106.)

Shuman, C.A. and 6 others. 2006. ICESat Antarctic elevation data: preliminary precision and accuracy assessment. Geophys. Res. Lett., 33(7), L07501. (10.1029/2005GL025227.)

Tapley, B.D., S. Bettardpur, M. Watkins and C. Reigber. 2004. The gravity recovery and climate experiment: mission overview and early results. Geophys. Res. Lett., 31(9), L09607. (10.1029/ 2004GL019920.)

Thomas, R. and 17 others. 2004. Accelerated sea level rise from West Antarctica. Science, 306 (5694), 255-258.

Thomas, R., E. Frederick, W. Krabill, S. Manizade and C. Martin. 2006. Progressive increase in ice loss from Greenland. Geophys. Res. Lett., 33(10), L10503. (10.1029/2006GL026075.)

Thompson, D.W.J. and S. Solomon. 2002. Interpretation of recent Southern Hemisphere climate change. Science, 296(5569), 895-899.

Van de Berg, W.J., M.R. van den Broeke, C.H. Reijmer and E. van Meijgaard. 2006. Reassessment of the Antarctic surface mass balance using calibrated output of a regional atmospheric climate model. J. Geophys. Res., 111(D11), D11104. (10.1029/ 2005JD006495.)

Velicogna, I. and J. Wahr. 2005. Greenland mass balance from GRACE. Geophys. Res. Lett., 32(18), L18505. (10.1029/ 2005GL023955.)

Velicogna, I. and J. Wahr. 2006. Measurements of time-variable gravity show mass loss in Antarctica. Science, 311(5768), 1754-1756.

Wahr, J., S. Swenson and I. Velicogna. 2006. Accuracy of GRACE mass estimates. Geophys. Res. Lett., 33(6), L06401. (10.1029/ 2005GL025305.)

Wingham, D.J. 2000. Small fluctuations in the density and thickness of a dry firn column. J. Glaciol., 46(154), 399-411.

Wingham, D.J., A.L. Ridout, R. Scharroo, R.J. Arthern and C.K. Shum. 1998. Antarctic elevation change from 1992 to 1996. Science, 282(5388), 456-458.

Wingham, D.J., A. Shepherd, A. Muir and G.J. Marshall. 2006. Mass balance of the Antarctic ice sheet. Philos. Trans. R. Soc. London, Ser. A, 364(1844), 1627-1635.

Zwally, H.J. and J. Li. 2002. Seasonal and interannual variations of firn densification and ice-sheet surface elevation at Greenland summit. J. Glaciol., 48(161), 199-207.

Zwally, H.J., W. Abdalati, T. Herring, K. Larson, J. Saba and K. Steffen. 2002. Surface melt-induced acceleration of Greenland ice-sheet flow. Science, 297(5579), 218-222.

Zwally, H.J. and 7 others. 2005. Mass changes of the Greenland and Antarctic ice sheets and shelves and contributions to sea-level rise: 1992-2002. J. Glaciol., 51(175), 509-527. 